\title{
Maximizing storage rates and capacity of carbon dioxide sequestration in saline reservoirs
}

\author{
A. Abou-Sayed ${ }^{1}$, Q. Guo ${ }^{2}$, A. L. Graham ${ }^{3}$, L. A. Mondy ${ }^{4}$, \\ M. S. Ingber ${ }^{5} \&$ A. A. Mammoli ${ }^{5}$ \\ ${ }^{1}$ Advantek International, USA \\ ${ }^{2}$ M-I Swaco, USA \\ ${ }^{3}$ Los Alamos National Laboratory, USA \\ ${ }^{4}$ Sandia National Laboratories, USA \\ ${ }^{5}$ Department of Mechanical Engineering, \\ University of New Mexico, USA
}

\begin{abstract}
The Kyoto Accords have been signed by 140 nations in order to significantly reduce carbon dioxide emissions into the atmosphere in the medium to long term. In order to achieve this goal without drastic reductions in fossil fuel usage, carbon dioxide must be removed from the atmosphere and stored in acceptable reservoirs. Research has been undertaken to develop economical new technologies for the transfer and storage of carbon dioxide in saline aquifers. In order to maximize the storage rate, the aquifer is first hydraulically fractured in a conventional well stimulation treatment with a slurry containing solid proppant. Well fracturing would increase the injection volume flowrate greatly. In addition, there are several ancillary benefits including extension of the reservoir early storage volume by moving the carbon dioxide further from the well. This extended reach would mitigate the problems with the buoyant plume and increase the surface area between the carbon dioxide and the formation facilitating absorption. A life-cycle cost estimate has been performed showing the benefits of this approach compared to injection without fracturing.

Keywords: carbon dioxide sequestration, reduction of green house gases, hydraulic fracturing.
\end{abstract}




\section{Introduction}

Substantial reduction of carbon dioxide $\left(\mathrm{CO}_{2}\right)$ emissions to the atmosphere will require economical and long-term stable sequestration in geological formations. Of the three possible types of formations, oil fields, coal beds and deep saline aquifers, the latter offer the most attractive long-term solution for several reasons.

- The capacity of saline aquifers is sufficient to accomodate disposal of $\mathrm{CO}_{2}$ for the foreseeable future $[3,6]$.

- Aquifers are close to a large percentage of the $\mathrm{CO}_{2}$ production sources in North America [1].

- Brackish waters in these formations are an ideal storage medium, since they are not suitable for potable water usage or even irrigation [2].

- Sequestration in these formations does not present health risks [4].

Several studies have been performed to establish the feasibility of $\mathrm{CO}_{2}$ sequestration in geological formations $[7,1,5]$. These studies have identified several issues as impediments to the economical viability of sequestering $\mathrm{CO}_{2}$ in deep saline aquifers and other geological formations. These issues include the injection rate and pressure required to achieve the required throughput and the long-term containment of $\mathrm{CO}_{2}$. In particular, in these previous studies, the injection pressure was limited by the fracture pressure of the formation, thus severely limiting the injection rate. In the current research, both the injection rate issue and the containment issue are addressed in a unified manner by intentionally fracturing the formation. Not only can the injection rate be substantially increased but the $\mathrm{CO}_{2}$ is spread further from the well-bore early in the injection process and the surface area between the injected supercritical gas and the formation is also substantially increased. These last two factors significantly reduce the problem of any buoyant plume of $\mathrm{CO}_{2}$ forming near the well-bore, and hence, seeping out of the formation. A life-cycle cost estimate of sequestration with and without hydraulic fracturing is performed to show the advantages of the current approach.

\section{Estimate of the relative costs for injection of $\mathrm{CO}_{2}$ into saline aquifers}

The current analysis of the life-cycle cost estimate to sequester $\mathrm{CO}_{2}$ from a coalburning power plant is based on a $800 \mathrm{MW}$ plant for a period of 20 years. The separation costs of the $\mathrm{CO}_{2}$ from the waste stream, the transportation costs, and the compression costs are not included. It is tacitly assumed that the saline aquifer will be in the proximity of the power plant so that transporting the $\mathrm{CO}_{2}$ to the injection site will be minimal. An analysis of acceptable aquifer locations was performed and several candidate formations were identified including several in the Central Appalachian Basin of western Pennsylvania, eastern Ohio, and eastern Kentucky and the San Juan basin in New Mexico. It is estimated that a $\mathrm{CO}_{2}$ injection rate of $12,600 \mathrm{~m}^{3} /$ day will be required by the $800 \mathrm{MW}$ power plant. An analysis is performed to determine the number of required injection wells 


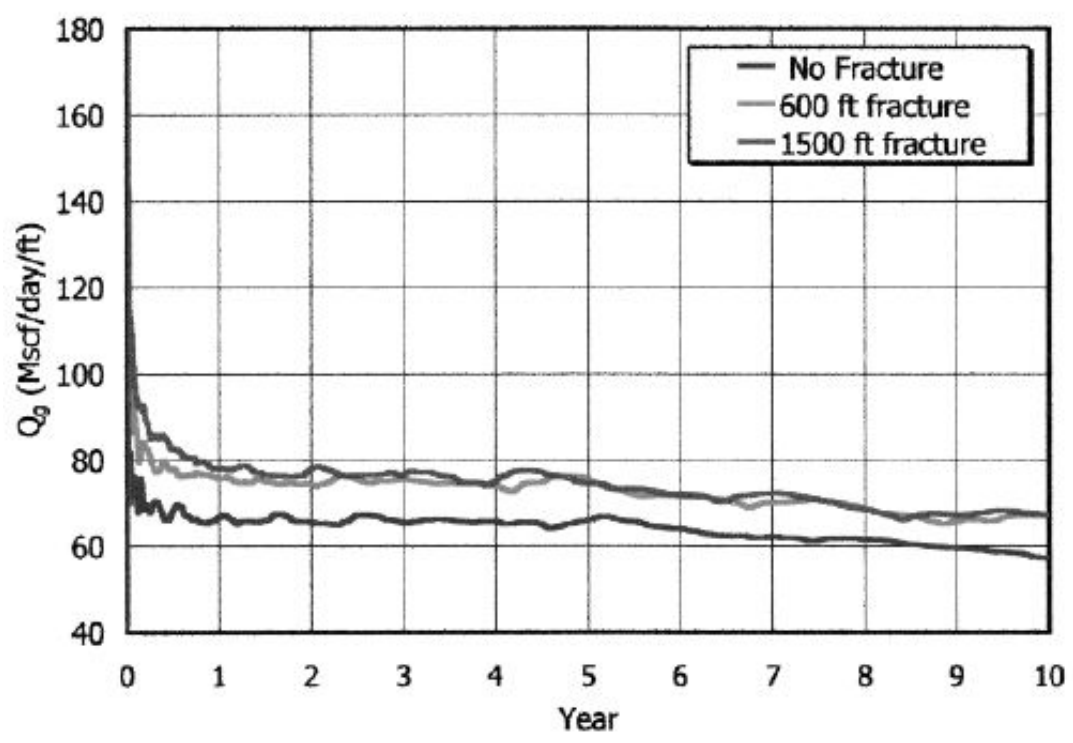

Figure 1: Injection flow rate as a function of time for fractured and non-fractured injectors.

depending on process including injection from non-fractured vertical wells, fractured vertical wells, non-fractured horizontal wells, and fractured horizontal wells. As an example, an analysis has been performed to measure the injection rate as a function of time for both a hydraulically fractured and non-fractured injector. Fig. 1 shows the injection rate as a function of time at a given injection pressure (equivalent to the constant compression pressure at the surface). Not only does the injection rate increase with fracturing, but also, the life of the well is also increased from approximately 5 years to approximately 20 years.

In the current analysis, the existence of an impermeable stress barrier is assumed, and hence, the $\mathrm{CO}_{2}$ will only flow through the sequestration zone and the bottom-hole injection pressure is limited at a value below the minimum horizontal in situ stress of the barrier. The required number of wells was determined from either radial flow equations or the flow equations of fractured injectors. The drilling, completion and fracturing capital expenditures (CAPEX) are considered as a lump sum that is accounted for in the year the operation takes place only. A more thorough analysis would take into account both the tangible and intangible value of the asset and spread it over a given number of years. Both the maintenance and man power costs, operating expenditures (OPEX) are considered to be fixed amounts that are deducted on a yearly basis. At the end of a well life, an abandonment cost capital expenditure is considered. Another operating expenditure associated with the process is power, which makes up the largest part of the operating costs. In cases where a hydraulic fracturing stimulation is 
Table 1: Input parameters considered for the cost model. All dollar values are in millions of dollars $(\mathrm{mm} \$)$.

\begin{tabular}{|c|c|c|}
\hline \hline Operations & Value & Unit \\
\hline Drilling & 2.00 & $\mathrm{~mm} \$$ \\
Hydraulic Fracturing & 0.30 & $\mathrm{~mm} \$$ \\
Abandonment & 0.40 & $\mathrm{~mm} \$$ \\
Compressor & 3.00 & $\mathrm{~mm} \$$ \\
Retrofit & 0.30 & $\mathrm{~mm} \$$ \\
Pipeline & 1.00 & $\mathrm{~mm} \$ / \mathrm{mile}$ \\
Distance & 2.00 & $\mathrm{mile}$ \\
Power & 10.00 & $\mathrm{cents} / \mathrm{kWhr}$ \\
Maintenance & 0.05 & $\mathrm{~mm} \$ / \mathrm{year} / \mathrm{well}$ \\
Labor & 0.12 & $\mathrm{~mm} \$ / \mathrm{person} / \mathrm{well}$ \\
\hline \hline
\end{tabular}

required an extra cost is added to the drilling cost for the fracture job, which again comes under capital expenditure. Finally all the costs are transferred their respective years and a discount rate is considered to establish the Net Present Value of the option. Table 1 shows the input parameters considered in the model for cost estimation.

In the first scenario, the viability of using a vertical well operating under matrix conditions is considered. The initial skin in this case is present due to formation damage from the drilling process and the type of completion used, and has an adverse effect on the injection process. It was found that a minimum of four wells were required to completely dispose of the $\mathrm{CO}_{2}$ generated from the 800 MW power plant. Furthermore, it was concluded that vertical unfractured wells would only operate under these conditions for five years at which point another four wells would be drilled, at another remote location, requiring a new compressor and pipeline connections. With eight wells now operational, both the maintenance and manpower costs are increased. One benefit of that scenario is that the injection rate can be decreased significantly among the eight wells, and hence, the wells would last for another seven years at which point another four wells would need to be added, and the process is repeated. No further wells would need to be added for the twenty year period of analysis. In the second scenario, the case of a vertical well that has initially been stimulated using hydraulic fracturing that creates a limited length contained fracture is considered. The effect on the injection process is notable and the previously adverse skin effect is overcome by the fracturing. The well's daily capacity is significantly increased for the same injection pressure. In this case, only two wells are needed and the wells will operate for the 


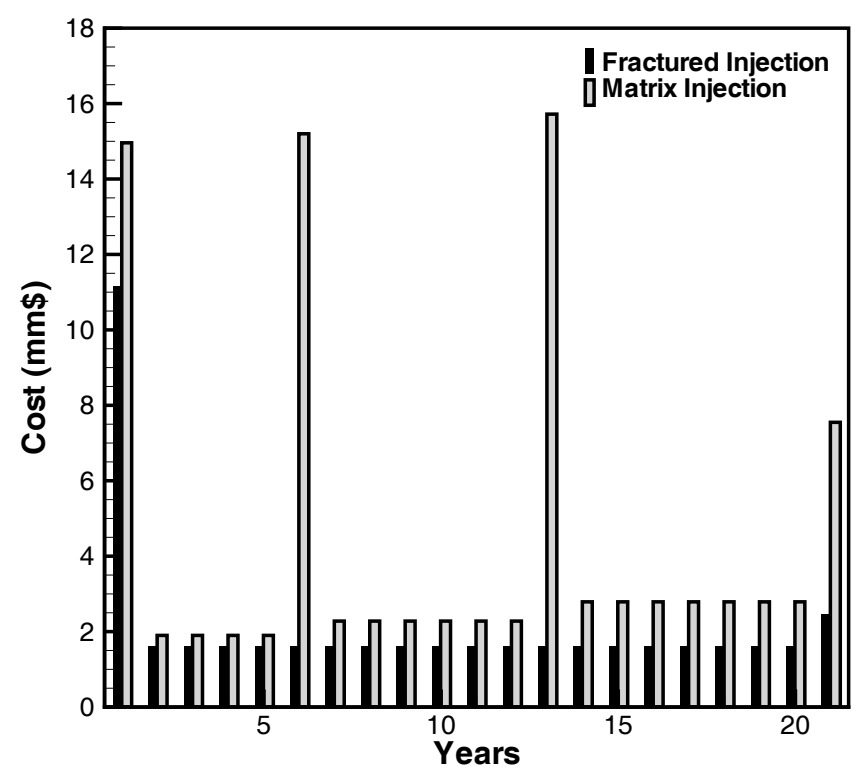

Figure 2: Yearly expenditures in millions of dollars for fractured injection and matrix injection.

duration of the twenty years. The total yearly expenditure for both the matrix injection and fractured injection are shown in Fig. 2. For the matrix injection scheme expenditure, there are several spikes denoting the repeated drilling phases discussed earlier and the final abandonment cost is much greater than that for the fractured injector scheme since the number of wells to be disposed of is considerably larger. Operating costs are increased for the matrix injection after each set of new wells is drilled caused by the increase in both man power and maintenance costs for the added wells. A break down of the costs per year of the two options (matrix injection and fractured injection) is shown in Table 2. The cost per year of matrix injection is over twice the cost per year of fractured injection. The Net Present Value (NPV) of each option was also determined. The NPV of fractured injection was calculated to be $-25 \mathrm{~mm} \$$ whereas the NPV of matrix injection was calculated to be $-50 \mathrm{~mm} \$$, thus demonstrating that fractured injection is a far more economically viable option.

Several additional cases were considered for horizontal injectors although a complete economic analysis was not carried out. From an engineering point of view, horizontal injectors would improve injection dramatically, and, in most cases, only one horizontal well with fractures is required. Consequently, this can greatly improve the economics of $\mathrm{CO}_{2}$ sequestration. The number of required wells and the associated flow rate and pressure is shown for a variety of injector geometries in Fig. 3. As seen in the figure, a horizontal well with 4 fractures can achieve the required daily flow rate at the minimum pressure. 
Table 2: Cost of the fractured and matrix option per year.

\begin{tabular}{|c|c|c|}
\hline \hline \multirow{2}{*}{} & \multicolumn{2}{|c|}{ Cost $(\mathbf{m m} \mathbf{)} /$ Year } \\
\cline { 2 - 3 } & Fractured & Matrix \\
\hline Drilling & 0.2 & 1.2 \\
Hydraulic Fracturing & 0.03 & 0 \\
Abandonment & 0.04 & 0.24 \\
Compressor & 0.15 & 0.45 \\
Pipeline & 0.1 & 0.3 \\
Power & 1.5 & 1.5 \\
Maintenance & 0.11 & 0.46 \\
Labor & 0.13 & 0.55 \\
\hline \hline
\end{tabular}

\begin{tabular}{|c|c|c|c|c|}
\hline \multicolumn{2}{|c|}{$\begin{array}{c}\text { Injector Scenarios for } \\
\text { Immiscible gas }\end{array}$} & $\begin{array}{c}\text { Number } \\
\text { Of wells } \\
\text { Needed }\end{array}$ & $\begin{array}{c}\text { Rate } \\
\text { (m3/day) } \\
\text { Per well }\end{array}$ & $\begin{array}{c}\text { Wellhead } \\
\text { Pressure } \\
\text { (kPa) }\end{array}$ \\
\hline & Matrix & 4 & 7200 & 6895 \\
\hline & $\begin{array}{c}\text { Fractured } \\
\text { (180m) }\end{array}$ & 2 & 18500 & 6895 \\
\hline & $\begin{array}{c}\text { Horizontal } \\
(1200 m \text { No fracture) }\end{array}$ & 1 & 25200 & 6827 \\
\hline & $\begin{array}{c}\text { Horizontal } \\
(1200 m \text { 4 fractures) }\end{array}$ & 1 & 25200 & 2177 \\
\hline & $\begin{array}{c}\text { Horizontal } \\
\text { (600m No fracture) }\end{array}$ & 2 & 20900 & 6895 \\
\hline & $\begin{array}{c}\text { Horizontal } \\
\text { (600m 4 fractures) }\end{array}$ & 1 & 25200 & 2315 \\
\hline
\end{tabular}

Figure 3: Injection rates and pressures for a variety of injector geometries. 


\section{Conclusions}

Saline aquifers have adequate capacity to serve as reliable sites for carbon dioxide sequestration for the foreseeable future. However, for low permeability formations, hydraulic fracturing of the injectors is necessary to achieve reasonable sequestration rates. The appropriate fracture length depends on the formation permeability and geomechanics moduli, stresses, and strengths of the different vertical lithologies of the subsurface column at the injection site. The effectiveness of vertical fractures in enhancing carbon dioxide injectivity increases as the reservoir absolute permeability decreases. The full life-cycle economic analysis indicates that costs can be greatly reduced by using fractured injectors compared to matrix injection. In addition, the use of properly designed fractured injectors, instead of injection in naturally fractured formations provide an assurance process for the fate and extent of the injected $\mathrm{CO}_{2}$ plume.

\section{Acknowledgments}

This work was partially supported by the U. S. Department of Energy (DOE) under grants DE-FG03-97ER14778 and DE-FG03-97ER35332. This financial support does not constitute an endorsement by the DOE of the views expressed in this paper. This work was supported by Los Alamos National Laboratory for the DOE under contract DE-AC04-94AL85000 and by Sandia National Laboratories for the DOE under contract DE-AC04-94AL85000.

\section{References}

[1] Bergman, P. D. and Winter, E. M., "Disposal of carbon dioxide in aquifers in the US," Energy Convers. Mgmt., 36(6-9), 523-526, 1995.

[2] Gunter, W. D., Perkins, E. H., and McCann, T. J., "Aquifer disposal of $\mathrm{CO}_{2}$ rich gases: Reaction design for added capacity," Energy Convers. Mgmt., 34(9-11), 941-948, 1993.

[3] Hendriks, C. A. and Blok,K., "Underground storage of carbon dioxide," Energy Convers. Mgmt., 34(9-11), 949-957, 1993.

[4] Koide, H, Tazaki, Y., Noguchi, Y., Nakayama, S., Iijima, M., Ito, K., Shindo, Y., "Carbon dioxide injection into useless aquifers and recovery of natural gas dissolved in fossil water," Energy Convers. Mgmt., 33(5-8), 619-626, 1992.

[5] Law, D. H.-S. and Bachu, S., "Hydrogeological and numerical analysis of $\mathrm{CO}_{2}$ disposal in deep aquifers in the Alberta sedimentary basin," Energy Convers. Mgmt., 37(6-8), 1167-1174, 1996. 
[6] Reichle, D., Houghton, J., Kane, B., Ekmann, J., Benson, S., Clarke, J., Dahlman, R., Hendrey, B., Herzon, H., Hunter-Cervera, J., Jacobs, G., Judkins, R., Ogdent, J., Palmisano, A., Socolow, R., Stringer, J., Surles, T., Wolsky, A., Woodward, N., and York, M., "Carbon Sequestration - State of the Science," Working Paper on Carbon Sequestration Science and Technology, U.S. Department of Energy, Office of Science, 1999.

[7] Van der Meer, L., "The $\mathrm{CO}_{2}$ storage efficiency of aquifers," Energy Convers. Mgmt., 36(6-9), 513-518, 1995. 